\title{
VIBRA-SENSORS PXI-BASED TEST COMPLEX CONTROLLED BY LABVIEW
}

\author{
Alexey Borisov ${ }^{a}$, Leonid Kessarinskiy, Dmitry Boychenko \\ National Research Nuclear University MEPhI (Moscow Engineering Physics Institute), 115409, \\ Moscow, Russia
}

\begin{abstract}
The article devoted to construction of an automated test complex for parametric and functional control of vibra-sensors ICs (such as integrated accelerometers and MEMS-generators). The test complex based on PXI-standard measurement devices and controlled by LabVIEW soft. The complex's characteristics was confirmed by calibration service and been certified.
\end{abstract}

\section{Introduction}

Vibration-sensitive devices such as accelerometers and MEMS-generators, are widely used in industrial and space systems with external factors hardness requirement. Consequently it required to provide laboratory hardness tests with functional and parametric samples control of such sensors [1-4].

Most of the available today on the market test solutions (EMIC, Sentek Dynamics, Thermotron, TIRA) are designed for vibration tests without additional external factors. They are quite bulky, multipurpose devices, and unsuitable for external factors test. Besides standard vibration testers are used for rather big and heavy device-under-test, for example packaging box of ICs, and are excessive for single chip. The aim of creation custom PXIbased test complex was to provide vibration-sensitive devices tests for microchips or micromodules [5-10] weighing typically less than 100 grams. So there was a need to create test complex answered to next requirements:

- Mobility.

- The possibility to set the vibration to a wide range of frequency and vibroacceleration.

- The possibility of automated controlling of frequency and vibroacceleration.

- The possibility to integration into the existing test complexes.

The work is devoted to present a custom designed automated test complex for parametric and functional control of vibration-sensitive devices during the radiation testing.

\section{Hardware and software}

First step was to define an executive part of the complex, includes a source of vibration and a power amplifier for this source, and then to convert a software commands to executive hardware vibration.

a Corresponding author: aybor@spels.ru 
An executive hardware action was based on an electrodynamics vibration table with a requirement mobility rate and amplitude.

The photo of a designed executive part is shown on Figure 1.

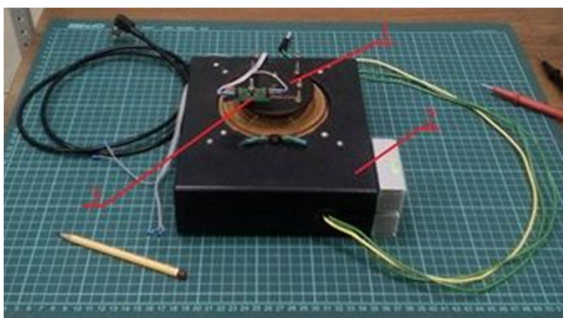

Figure 1. The appearance of the executive part: 1) audio speaker, 2) power amplifier,

3) accelerometer.

The main parts of the vibro-table are described below.

1) Audio speaker

The audio speaker with large diameter of a membrane and 80 watts of electrical power was chosen as the basis of executive part of a complex. The audio speaker has wide bandwidth that allows for a wide range of vibration frequency.

2) Power amplifier

The audio speaker supplied from the audio amplifier corresponding by electrical power. High electrical power and diameter of the speaker membrane provides a wide range of vibroacceleration. Small size of the executive part provides mobility.

3) Accelerometer

Full automation of parametric and functional control process is possible by reference through high speed accelerometer with analog output.

\section{Solution}

\section{1) Hardware part}

Represented executive part was certified in the prescribed manner. Achieved charachteristics of the vibration load is shown in Table 1.

Table 1. Characteristics of the executive part of complex.

\begin{tabular}{|c|c|c|}
\hline Name of parameter & Minimum & Maximum \\
\hline Vibro acceleration & $0.05 \mathrm{~g}$ & $1.5 \mathrm{~g}$ \\
\hline Frequency & $5 \mathrm{~Hz}$ & $1.5 \mathrm{kHz}$ \\
\hline
\end{tabular}

The next step of the complex development was solving the problem of integration one to existing external factors hardness test complexes based on the National Instruments PXIstandard measurement devices. Another words it needed to developed PXI-based controller with LabVIEW soft.

Functional generator PXI-5402 used as a setting device for form and amplitude of the oscillation, a vibroacceleration setting. High accuracy of vibroacceleration defining was achieved by sufficient precision of output amplitude.

Output voltage amplitude of these accelerometer measured by PXI-5114 oscilloscope. The software calculate vibroacceleration and thereafter and adjust the output amplitude of PXI-5402 functional generator.

2) Software part

The system's software was created NI LabVIEW. Front panel of electrodynamic vibration 
table control program is shown on Figure 2.

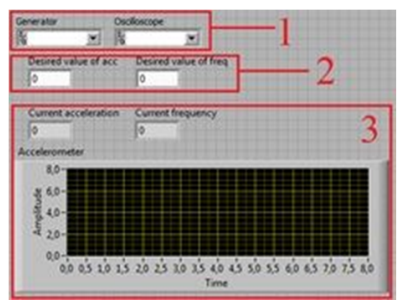

Figure 2. Front panel of control VI: 1) block of initialization, 2) block of desired parameters setting, 3) block of reached values.

To use the program must enter the desired frequency and acceleration.

Measured acceleration sensor, or any other device under test can be mass comparable to the mass of the movable part vibrating table, it can change the resonant frequency of the system. The same effect on the resonance frequency is the presence in the device own resonant frequencies, if present massive moving parts in its composition. Unpredictable change in the resonant frequency may result in a sharp increase in acceleration at this point, which may be critical for some devices and cause their destruction. Thus, by measuring the transfer characteristics of the object and just when moving from one frequency to another, there is a need for a smooth change of the oscillation frequency by adjusting the amplitude of a continuous acceleration in order to maintain a predetermined level. The main parts of the software are shown in Figures 3 and 4.

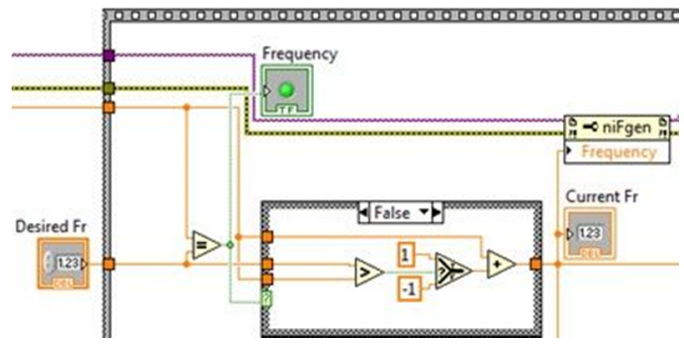

Figure 3. Smooth change of the oscillation frequency.

The first step in the algorithm is the frequency change in the desired direction. The current frequency is compared to the entered in the appropriate box on the front panel of the value of the desired frequency, if these values do not match, is given to the frequency change command in the direction desired by a small amount. Figure 4 corresponds to the minimum change in frequency of $1 \mathrm{~Hz}$, but, depending on the task, the equipment allows to change the frequency in increments of up to $1 \mathrm{mHz}$. After the change of vibroacceleration occurs check for compliance specified in the appropriate box on the front panel. Measured current value of the acceleration by reading from the accelerometer readings in a few oscillation periods, subtracting from the resulting waveform DC component (acceleration of gravity), and calculate the actual maximum acceleration on the basis of the oscillation amplitude and the sensitivity of the accelerometer in this case is $0.66 \mathrm{~V} / \mathrm{g}$.

If the measured acceleration measurements fit within acceptable boundaries, the algorithm proceeds to further tuning frequency. If the measured value is out of range, then the value of the gain generator modified to decrease or increase, then the measurement is repeated and the change in gain continues until the desired acceleration values, and then repeats step frequency control.

Thus, the application of this algorithm allows you to change the frequency and acceleration values smoothly within a wide range and, thus, does not exceed the permissible 
limits on acceleration $[12,13]$.

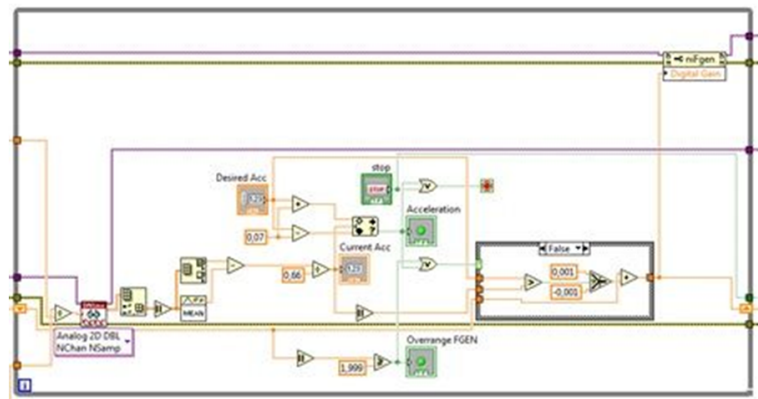

Figure 4. Smooth change of the vibroacceleration.

\section{Implementation and its prospects}

The developed automated complex allows automatically measured all of the criterial parameters such as frequency response function of a vibration-sensitive devices during the radiation tests at other environmental conditions and facilities (pulsed electron accelerators, electron LINACs, X-ray testers etc.) [11].

The developed automated system has successfully implemented at JSC "ENPO SPELS", Moscow, Russia.

\section{Acknowledgment}

The paper is a part of the research done within the government assignment RFMEFI57414X0115 given by the ministry of education and science of Russian Federation.

\section{References}

[1] A. S. Artamonov, D. V. Boychenko, A.Y. Nikiforov, A. V. Sogoyan, N. A. Shelepin, V. A. Telets, M. G. Tverskoy, Proceedings of the European Conference on Radiation and its Effects on Components and Systems (RADECS) 1, 296 (2002)

[2] V. V. Belyakov, V. S. Pershenkov, G. I. Zebrev, A. V. Sogoyan, A. I. Chumakov, A.Y. Nikiforov, P. K. Skorobogatov, Mikroelektronika 32, 31 (2003)

[3] V. V. Belyakov, A. I. Chumakov, A.Y. Nikiforov, V. S. Pershenkov, P. K. Skorobogatov, A. V. Sogoyan, Mikroelektronika 32, 134 (2003)

[4] V. V. Belyakov, V. S. Pershenkov, G. I. Zebrev, A. V. Sogoyan, A. I. Chumakov, A.Y. Nikiforov, P. K. Skorobogatov, Russian Microelectronics 32, 25 (2003) doi: $10.1023 / \mathrm{A}: 1021809802818$

[5] D. V. Boychenko, A.Y. Nikiforov, P. K. Skorobogatov, A. V. Sogoyan, Proceedings of the European Conference on Radiation and its Effects on Components and Systems (RADECS), 5205522 (2007) doi: 10.1109/RADECS.2007.5205522

[6] A. V. Grebenkina, D.V. Boychenko, A.Y. Nikiforov, V. A. Telets, V. V. Amelichev, V.A.Kharitonov, Proceedings of the International Conference on Microelectronics (ICM), 133 (2014) doi: 10.1109/MIEL.2014.6842103

[7] A. B. Boruzdina, A. A. Orlov, A. V. Ulanova, N. G. Grigor'ev, A.Y. Nikiforov, Proceedings of the International Siberian Conference on Control and Communications (SIBCON), 7147007 (2015) doi: 10.1109/SIBCON.2015.7147007 
[8] I.O.Loskutov, A. B. Karakozov, P.V. Nekrasov, A.Yu. Nikiforov, Proceedings of the International Siberian Conference on Control and Communications (SIBCON), 7147128 (2015) doi: 10.1109/SIBCON.2015.7147128

[9] I.I. Shvetsov-Shilovskiy, P.V. Nekrasov, A.V. Ulanova, A.A. Smolin, A. V. Sogoyan, Proceedings of the International Siberian Conference on Control and Communications (SIBCON), 7147282 (2015) doi: 10.1109/SIBCON.2015.7147282

[10] V. A.Marfin, P.V. Nekrasov, O. A. Kalashnikov, K. A. Kagirina, Proceedings of the International Siberian Conference on Control and Communications (SIBCON), 7147142 (2015) doi: 10.1109/SIBCON.2015.7147142

[11] A.S. Artamonov, A.A. Sangalov, A.Y. Nikiforov, V. A. Telets, D.V. Boychenko, IEEE Radiation Effects Data Workshop 2015-January, 7004600 (2014) doi: 10.1109/REDW.2014.7004600

[12] D. Hartono, D. Halim, A. Widodo and G.W. Roberts, MATEC Web of Conferences, 65, 1003 (2016) doi: 10.1051/matecconf/20166501003

[13] Zhi Zhou, MATEC Web of Conferences 65, 5001 (2016) doi: $10.1051 /$ matecconf $/ 20165905001$ 